\title{
Analysis of Blended Learning Scheme Based on Cloud Computing Assisted Instructions
}

\author{
http://dx.doi.org/10.3991/ijet.v11i03.5535 \\ Zeyu Sun ${ }^{1,2}$, Yunxing Shu ${ }^{1}$ \\ ${ }^{1}$ Luoyang Institute of Science and Technology, Luoyang, China \\ ${ }^{2}$ Xi'an Jiaotong University, Xi'an, China
}

\begin{abstract}
With the development of science and technology, cloud computing technology has been widely applied in a variety of engineering fields, while its application and promotion in the education is always neglected. In this paper, the cloud computing assisted hybrid learning scheme is put forward based on the analysis of the cloud computing technology and the hybrid method. Firstly, the cloud computing platform architecture and key technology are explained. Secondly, the four stages of the blended learning scheme model are established in accordance with its guiding ideology and construction principle. Furthermore, the four stages are given a detailed description and analysis in which seven blended teaching links are concluded in combination with Baihui cloud platform application characteristics. Finally, the scores from students of different grades and different years are compared. The result of comparison shows that the blended learning scheme is effective in the classroom and helpful to stimulate the students' learning interest and enthusiasm, which is significant for the further in-depth study.
\end{abstract}

Index Terms-blended learning, Cloud Computer Assisted instruction (CCAI), information technology education

\section{INTRODUCTION}

With the rapid development of information technology, the course of fundamentals of computers has been one of the common compulsory courses for non-computer majors in all the colleges and universities. Its teaching objective is to nurture high level compound talents with innovative ability. The course help students to be able to master the skills and techniques of operating computer as well as with solid expertise and professional skills. With this skills, the students can not only lay solid foundation for the further study, but can also, improve their employment ability [1-2]. It was successfully implemented for several years in order to improve the teaching effectiveness of the course. All the colleges and universities have begun to organize the faculty to perform a set of reform and research in teaching methodology and learning methodology. Besides, many other aspects including combining the classroom instruction with classroom practice [3], applying the multimedia equipment to assist instructions, blending situational teaching and task-driven method to the classroom instructions, with a certain degree of success are in practice. However, these forms of teaching are still classroom teaching oriented. The teachers are the core of the class, which cannot reflect the concept of studentcantered, and the students are passive knowledge receivers. As a result, students gradually lose their interest in study.
The Cloud Computing provides safe and reliable data storage [4-5], convenient and quick web service with supercomputing ability. If the new technology can be applied in educational fields, and advantage of the service the cloud computing offers can be taken to assist instruction that will drive the process of the educational information. The distributed architecture and centralized architecture of cloud system can be shown in Figure 1 and Figure 2.

Under the background of the cloud computing, by adopting the teaching mode of task-driven collaborative learning, the teaching practices for the undergraduate courses are taken. In practice, the researchers can acquire the students' learning features in the collaborative learning progress, research the teachers' roles in the progress, and explore how to play the leading role. To design the task, to create scenes, and to build a platform for the collaborative

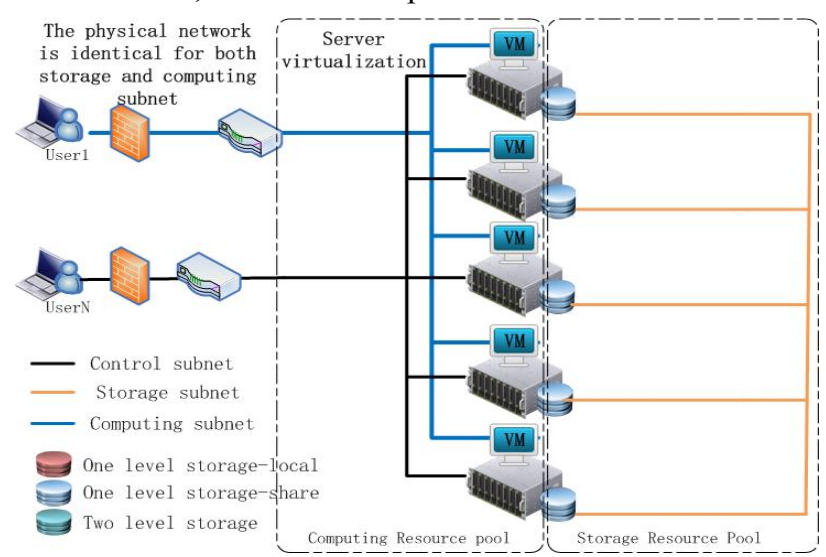

Figure 1. The distributed architecture of cloud system

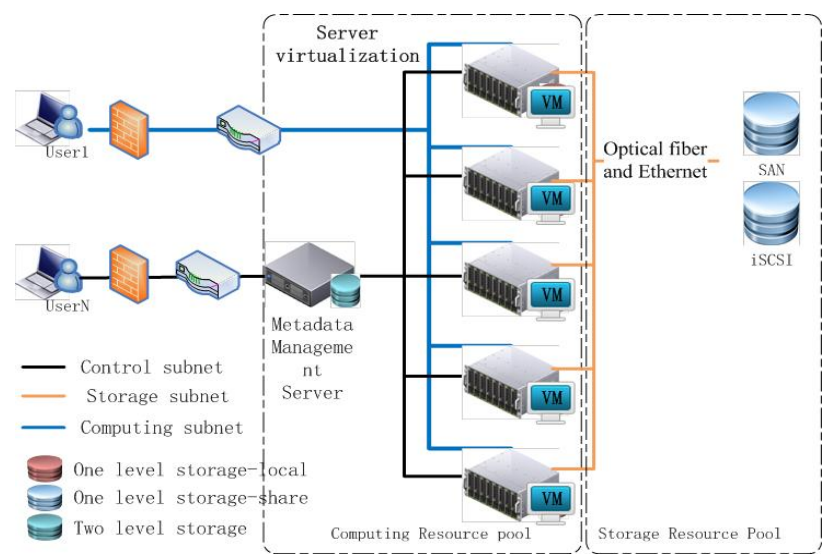

Figure 2. The centralized architecture of cloud system. 
learning effectively, whose aims are as the followings: Firstly, to start the task-based collaborative learning through the platform of cloud services. This will help the students not only master the teaching content, but strengthen their self-learning ability, the collaborative spirits, the collaborative learning abilities and upgrade the students' learning enthusiasm. Secondly, to explore patterns which is beneficial for the collaborative teaching in cloud services platform and to provide references and accumulate experience for other curriculums. Thirdly, to take the advantage of cloud computing to realize the schools' supplementary for the hardware and software teaching resources. Fourthly, combined with the latest concept-cloud computing to develop the exploration and research in the field of collaborative learning and to solve the practical problems in the teaching practices. It has strengthened the students' independent learning abilities and collaborative abilities and nurtured the students' overall qualities to meet the requirement of social development. Fifthly, through the teaching practice, the researchers have put forward the methods of utilizing the cloud services platform. They rethought about the teaching results and the problems existing in the teaching progress, and thus, provided references for the future teaching research under the cloud computing.

\section{LITERATURE REVIEW}

After entering in the Internet time, the information can be transferred on the internet in high speed, and changed the traditional educational philosophies and teaching modes. Yang B [6] gives an example of the use of collaboration platforms. He pointed out that the clouds computing assisted instruction's collaboration platform can solve the existing problems and put forward an effective clouds computing assisted instruction is the concept of collaborative design. Ma Q., et al [7] researched a series of typical problems in the cloud computing aided instruction-CCAI. The description of concepts related to CCAI, the analysis of basic situation of cloud design process about collaborative learning to CCAI which consists of select function modules and components., It organizes teaching resources, design activities about collaborative learning, and expand components with individual. Shang Y L., et al [8] constructed the environment of the cloud computing service platform by using the new concept of cloud computer assisted instruction and discusses its impacts on teachers and students. Jiang N., et al [9] proposed the application of a CCAI based on Zoho Wiki, through which the learners may improve their effective collaborative learning. The application also pointed out the limitation of CCAI. It includes the adequate online resources and the scientific design by the teachers who are responsible for the online courses. Xing Y L., et al [10] proposed to combine blended learning method with cloud computing assisted instruction in this course where mass of network resource enriches the classroom teaching and student's practice. It is expected that the teacher-student interaction could be enhanced and teaching quality to be improved. Xue H., et al [11] used cloud computing assisted instructions platform in teaching activities that can effectively motivate students' learning enthusiasm, improve teaching quality, and reduce operational cost of the school in order to achieve the goal of low carbon, energy-saving and environmental protection.

\section{METHODOLOGY}

\section{A. Analysis of Cloud Computing Assisted Instruction}

In recent years, scholars have integrated the cloud computing with the field of education and teaching. They advanced the concept of Clouds Computing Assisted Instruction (CCAI), expecting to improve the current teaching philosophy and teaching methodology [12]. The advance of the concept of cloud computing has simplified the learners' terminal equipment. It allowed the learners to get learning information and store learning resources through the browser whenever and wherever possible to carry out open learning. The term cloud computing has been prevalent in the world of information technology. The Computer Assisted Instruction, CAI in short, is a kind of computer-mediated means of assisted instruction. It is developed under the direction of educational theory, psychology, and communication theory. It's aim is to take the advantage of the computer technology to design and develop the learning resources, improve the teaching quality, construct a new teaching mode in order to achieve the teaching goal. The advantages of the Computer Assisted Instruction are as follows [13]: Firstly, it has realized the share of teaching resource through the Internet and the share of hardware and software teaching resources can be realized. The resources in the Internet are quite rich, for example, the texts, the videos, and the audios have the advantage of audio-visual, which benefit the students' multi-sensory to participate in the perception process. These resources can stimulate students' interest, promote the training of the students' creative thinking and the construction of knowledge system. Secondly, it has changed the traditional teaching method. In traditional teaching, teacher is the Centre, while in E-learning, student is the Center. In E-learning method, the students learn by themselves according to their needs, while the teachers only guide the students, teach the students in accordance with their aptitude, and help the students through the homework and assessment [14]. Besides, the students can communicate freely, which has foster the students' learning autonomy, initiative and effectiveness.

With the help of the cloud service, the process of the blended learning has been mainly designed into four parts: the early analysis stage, the specific design stage, the observation stage and the modified and perfecting stage. According to the concept, the guiding ideology and design philosophy of the blended learning supported by the cloud services. (1) The analysis of learning demand: Generally, the learning demand means the disparity between the learners' present study state and the state they want to get in the future. Specifically, it is necessary to explore the learners' current state, the learners' capacity demands, and the syllabus requirement for the learners. The analysis of learning demand is the beginning part and the center part is the whole design process. When the teaching procedure is being designed, it is necessary to analyze the learning demand properly. Only in this way, the whole teaching activities can be carried out successfully. (2) The analysis of the learners: The learners are the most important part of the whole instructional design procedure and can affect the result of the teaching activities. The concept of the learning can be expounded through the multimedia, by which the learners can gather knowledge autonomously based on their own conditions. (3) The analysis of learning environment: The learning environment plays an im- 
portant role in the learning procedure. A terrible learning environment will affect the learners' learning enthusiasm and learning efficiency. In the whole learning procedure it is ensured that: whether the schools' learning environment can meet the teaching requirement, whether the computer lab can connect to the Internet, whether the computers are equipped with proper software, whether the servers can provide the students opportunities to take the onlinelearning at the same time and whether the equipment malfunctions can be resolved and so on. These all are about the schools' learning environment. (4) The design of the learning activities: The design of the learning activities must be thought highly in the teaching process. Because the results of the learning activities affect the learning and general learning activities including the traditional classroom teaching and the blended learning on the cloud platform supported by the network technology.

\section{B. B. Cloud Computing Assisted Instruction Platforms}

The Software as a Service (SAAS) is one kind of cloud service. After joining the cloud computing service, the schools can use the applications for free or just paying very low money, which can reduce the cost of the construction of the information system and save the expense of the maintenance and upgrading of software. In recent years, all the colleges and universities have increased the investment in the construction of education resources, and accumulated plenty of instructional information resources. But among all the schools, the lack of the exchanges and cooperation has caused the duplicate constructions of the resources. The cloud computing can strengthen the exchange and cooperation among all the schools, promote the integration of the instructional resources, realize the maximum share of resources on the internet and finally realize the real meaning of resource sharing. Meanwhile, it is also favorable for the improvement of the current imbalanced distribution of instructional resources in the educational information network. In the age of the Internet, the quality of the Internet users is uneven. The inter- net ethics are unsatisfactory to the people according to their expectation. The computer virus are spreading unchecked, the computer hackers are rampant everywhere. Under this situation, the fact is that how to ensure the reliability and the safety of the stored data appears to be very important. The schools use the cloud computing service, and the data is stored in the cloud, no need to worry about the virus intrusion and the loss of data caused by crashing of hardware. The teachers can construct their own individualized teaching environment easily through the resources and services provided by the cloud computing without depending on the professional technical personnel. It has reduced the cost and lowered the threshold of teachers' Information and Technology Training; while for the students, under the help of the cloud computing, they can choose the learning contents and style freely, which have finally realized the improvement of the teachers' teaching quality and the training for the students' ability of collaborative learning. The cloud computing assisted instructions structure can be shown in Figure 3 .

\section{Blended Learning of Cloud Computing}

Under the blended learning based on the cloud platform, when designing the teaching plans, the guiding ideologies are as the following: (1) the blended learning supported by the cloud computing assisted platform emphasizes the learning constructions, and pays special attention to combine teachers' leading role and students' subjective role. It is mainly to integrate the traditional classroom teaching and the blended learning based on the cloud services platform. It also enhance the learning efficiency and the students' learning enthusiasm. (2) The key part of the blended learning based on the cloud services is the selection of instructional media. The blended learning is a kind of learning style which adopts the face-to-face communication in the traditional classroom, and takes advantages of the Internet to take the online and offline learning. Comparing with the traditional learning style, the

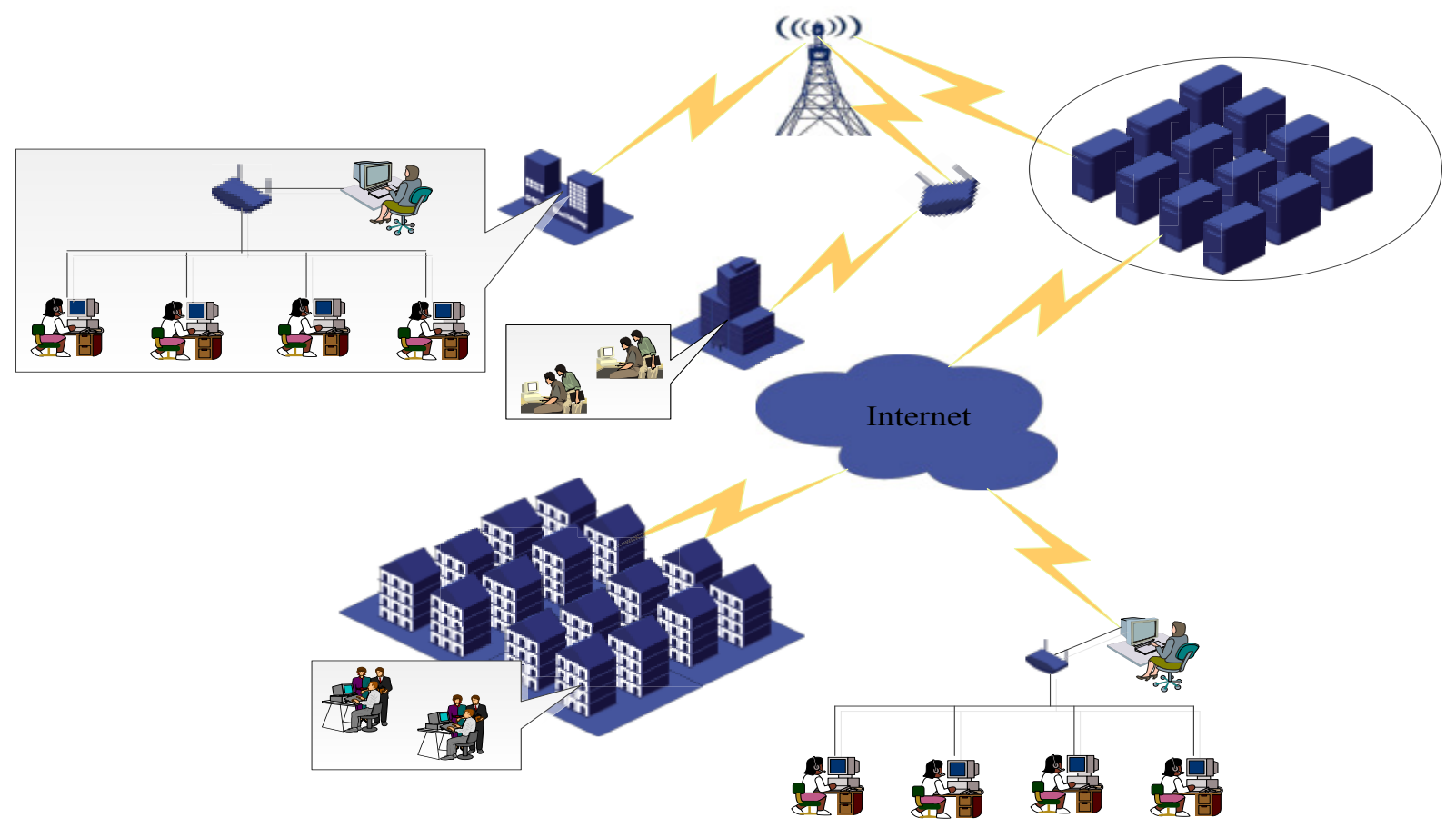

Figure 3. Cloud computing assisted instruction structure 
PAPER

learners don't have to look for ways to select the instructional media, but to learn with the help of the cloud platform, which has lowered the investment cost of learning, and enhanced the learning efficiency. (3) When taking about the blended learning, the most important thing is to study the way of delivering information. Different ways of delivering information bring the students to have different kinds of learning experience. And with the help of the instructional assisted platform which takes advantage of the cloud services, the students can engage in constructive study. When using the Baihui platform to take the assisted learning, there are the main adopted ways to deliver information, such as the online courses, online forums, collaborative learning etc. However, certain principles must be followed when designing all kinds of website, so as to the building of the Baihui Platform like: (1) The principle of purpose-oriented: Setting the corresponding learning goals plays an important role in the blended learning, and before the learning, the students should know what goal they want to achieve, and while reaching the goal, what they are going to learn and what kind of capabilities they need to develop. . Only having set a clear goal, the learners can take the systematic learning according to corresponding teaching aims. Through the specific practice, the teachers should guide the students how to set their general objective and staggered goal. (2) The technological applicability principle: In the teaching progress, the teachers choose teaching tools and software according to the classroom teaching content. However, all kinds of tools and software have their own advantages and disadvantages. In the teaching activities, when the teachers are selecting the tool and software, they need to meet the teaching requirements, and integrate them selectively. Only in this way, the function of the tools and software can obtain the maximum performance. The association for educational communications and technology has defined the educational technology: the Educational Technology is the theory and practice of designing, developing, utilizing, managing and evaluating the relevant progress and resources, which is in order to improve the learning. As the definition says, in the teaching progress, the design of the teaching resources is quite important when designing the courses and it's easy and quick to establish the teaching resources on the Baihui assisted instruction platform. Meanwhile, the technologies, especially the latest technologies, are quite taken seriously when applied in the teaching practice, which are based on the Baihui cloud platform. (3) The principle of advanced methods: The cloud platform which is set up by the Baihui has changed the traditional teaching philosophy. The application of Baihui cloud platform has changed the teaching philosophy, for example, the teaching content can be shown on the cloud platform; the learning method can be practiced on the cloud platform; and the learning environment can also be constructed on the cloud platform etc. And the teachers can switch the teaching philosophy with the help of cloud platform which are the principle of advanced methods reflected by the cloud platform. (4) The principle of interaction: it mainly means the applications of the learning activities can be operated. The Baihui cloud platform can give its feedback to the students' performance. It means that in the learning progress, the students must give feedback to the corresponding contents, but not just skimming through the ETextbook. (5) The principle of collaboration: In light of the design of the blended learning have to reflect the principle of collaboration. In the entire learning process, a complicated work can't be completed only by one person, but by a group of students to work together. The complicated work can be divided into several parts, and the students can work together to complete the work as a teamwork. This process can foster the learners' team spirits and the communication skills with others. The cloud platform can provide the learners with an excellent learning environment and provide free learning platform and free exchange platform for the collaborative learning. For example: the Baihui chatting, the Baihui forum etc.

Create a new teaching platform: Cloud computing to create a secondary teaching platform, not only broke the traditional classroom teaching learning mode, but also makes teaching platform to build the network more easily, while teaching at the time and space to be extended, make up the single classroom teaching methods inadequate. Increase the communication channels: In the traditional classroom model, teachers and students communication is limited to the classroom. Cloud computing platform enables teaching between teachers and students, to achieve real-time or asynchronous communication between life and life to share and enrich the means of communication. Expand the personalized learning space: through cloud computing assisted instruction, teachers can not only enrich the ways and teach learning methods, but also that learners develop personality of the new platform and space. Learners use cloud computing environment, planning personalized courses and self-learning management.

\section{RESUlTS OF ANALYSIS AND DisCUSSION}

As the cloud computing appears, there are some people begin to research the application of the cloud computing in the education and teaching fields. In the educational technology field, many experts have made detailed demonstrations in light of theory and practice in their articles and blogs. It is about the positive effect of the cloud computing assisted instructions in the modern education and teaching. Even in recent years, numerous masters and doctors have selected the cloud computing assisted instructions as their research object to demonstrate and write their papers. Plenty of the papers have explained the effects of mobile learning and blended learning in the teaching process of engineering field which is based on the cloud computing. They have made detailed quantitative and qualitative analysis on the effect of the cloud computing assisted instructions in the special learning in computer science including the theory learning, the practical ability and the application capability. The experiment used in the experiment is comparison one. The first important considerations are the experimental subject and the learning material adopted by the experiment. The experimental subject of this research is the undergraduate students of computer science and technology who are admitted in 2011. The experiment selected the students from 4 parallel classes as the experimental subject and the computer skill of the students are almost in the same level and have a lot of rooms for improvement. The computer network course of the 4 parallel classes is taught by the same teacher. In order to narrow the experimental error, before the experiment, a little adjustment for the students participating in the experiment has been made by controlling the number of each class at 117 . We made a comparative analysis of the result before the test and after the test. The Table 1 is the statistic table before the test, and Table II is the statistic table after the test. 
The results show that before the test, the students' average score of the Computer Network Architecture in the Experimental class A is 75.56. This score shows that the students' level of mastering the Computer Network Architecture is in the middle; the students' average score of the Computer Network Architecture in the control class B reaches 74.92. The score close to 75 shows that the students' level in the control class B is almost close to the middle level. From the comparison of the two groups of the figures, we could conclude that the difference of the score before the test is not very obvious. For the same reason, the levels of the experimental class $\mathrm{C}$ and the control class D are in the middle.

The statistics in Table II show that the students' average scores of the Computer Network Architecture in the experimental classes and in the control classes have been enhanced significantly. The average score of the experimental class A is 79.85 after the test, and it is 4.69 higher than that of before the test. What is more, the lowest score after the test is 69 , it is 6 higher than the lowest score before the test; and the highest score is 92 , higher than the highest score 89. The students' score of the Computer Network Architecture in the control class B after the score has been also increased. The average score after the test is 77.62 , higher 2.70 than that of before the test. Furthermore, the lowest score after the test is 65 , higher 4 than that of before the test; and the highest score is 90 , higher 3 than that of before the test. All of these show that the students' ability to the knowledge of the Computer Network Architecture has a general enhancement.

In order to validate the assumption in the Computer Network Architecture courses, the U-Learning assisted instructions based on the cloud computing has more advantages than the computer assisted Instructions. The researchers made an independent sample $t$ test having compared the students' scores of the computer network test in the experimental classes with that in the control classes. The test results is shown in Table III.

The average score of the Computer Network Architecture test in the experimental class $\mathrm{A}$ is 2.23 higher than that in the control class B; and the average score of the Computer Network Architecture Test in the experimental class $\mathrm{C}$ is 2.32 higher than that in the control class D. Through the independent sample $t$ test, the researchers found that after the computer network architecture test, Value $=0.000<0.005$, which also means the grade of the control classes represent some gaps among the experimental classes. Therefore, we can get a conclusion that in the Computer Network Architecture courses, the ULearning assisted instructions, based on the cloud computing has more advantages than the computer assisted instructions.

By the summary of the analysis of the professional courses of the 4 classes in different academic years, it shows in light of utilizing the internet and the online resources to learn knowledge. The levels of class A and class $\mathrm{C}$ are almost in the same one, and the levels of class $\mathrm{B}$ and class D are almost in the same one. Through comparing the 4 Classes' average scores of the final examination: The actual attendance to the final exam of class A is 30 students, the highest score of the class is 97 , and the average score of the class is 77.16; The actual attendance to the final exam of class B is 29 students, the highest score of the class is 92 , and the average score of the class is 74.12; The actual attendance to the final exam of class $\mathrm{C}$ is 29 students, the highest score of the class is 96 , and the average score of the class is 76.02; The actual attendance to the final exam of class D is 29 students, the highest score of the class is 94 , and the average score of the class is 73.91. It can be concluded that the level of class A is higher than class B, class C, class D.

TABLE I.

STATISTIC TABLE OF THE COMPUTER NETWORK ARCHITECTURE BEFORE THE TEST

\begin{tabular}{|l|c|c|c|c|c|c|}
\hline \multicolumn{1}{|c|}{ The Classification } & $\begin{array}{c}\text { Number of Sam- } \\
\text { ples }\end{array}$ & $\begin{array}{c}\text { Minimum } \\
\text { Score }\end{array}$ & $\begin{array}{c}\text { Maximum } \\
\text { Score }\end{array}$ & Average Score & S. D. & $\begin{array}{c}\text { S.D. of the } \\
\text { Average }\end{array}$ \\
\hline Experimental Class A & 30 & 63 & 89 & 75.16 & 2.594 & 0.382 \\
\hline Control Class B & 29 & 61 & 87 & 74.92 & 2.488 & 0.329 \\
\hline Experimental Class C & 29 & 61 & 89 & 75.07 & 2.102 & 0.364 \\
\hline Control Class D & 29 & 60 & 88 & 74.81 & 2.246 & 0.322 \\
\hline
\end{tabular}

TABLE II.

STATISTIC TABLE OF THE COMPUTER NETWORK ARCHITECTURE AFTER THE TEST

\begin{tabular}{|l|c|c|c|c|c|c|}
\hline \multicolumn{1}{|c|}{ The Classification } & $\begin{array}{c}\text { Number of Sam- } \\
\text { ples }\end{array}$ & Minimum Scores & $\begin{array}{c}\text { Maximum } \\
\text { Scores }\end{array}$ & Average Scores & S. D. & $\begin{array}{c}\text { S.D. of the } \\
\text { Average }\end{array}$ \\
\hline Experimental Class A & 30 & 69 & 92 & 79.85 & 2.033 & 1.679 \\
\hline Control Class B & 29 & 65 & 90 & 77.62 & 2.241 & 1.496 \\
\hline Experimental Class C & 29 & 67 & 95 & 79.71 & 2.102 & 1.599 \\
\hline Control Class D & 29 & 66 & 93 & 77.39 & 2.246 & 1.477 \\
\hline
\end{tabular}

TABLE III

INDEPENDENT SAMPLE T TEST OF THE COMPUTER NETWORK ARCHITECTURE THE TEST

\begin{tabular}{|l|c|c|c|c|c|}
\hline \multicolumn{1}{|c|}{ The Classification } & The Number of Samples & The Average Score & SD & \multirow{2}{*}{ Sig } \\
\hline Experimental Class A & 30 & 79.85 & 0.662 & \multirow{2}{*}{5.225} & \multirow{2}{*}{0.000} \\
\cline { 1 - 4 } Control Class B & 29 & 77.62 & 0.623 & & \multirow{2}{*}{5.218} \\
\cline { 1 - 4 } Experimental Class C & 29 & 79.71 & 0.659 & 0.000 \\
\hline Control Class D & 29 & 77.39 & 0.613 & & \\
\hline
\end{tabular}




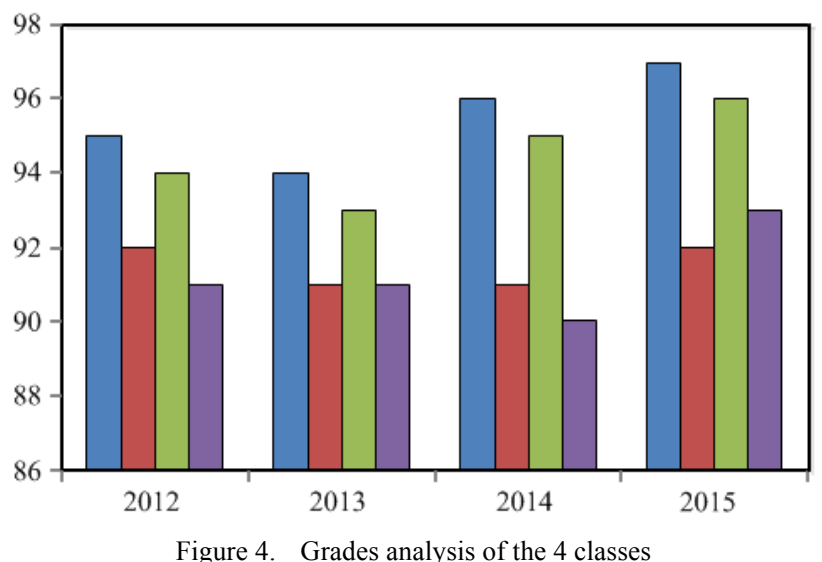

V. CONCLUSIONS

In this paper, the application of cloud computing assisted instruction platform in education are analyzed and studied. The computing technology is fully applied to build a teaching platform whose architecture and principles are further elaborated with the blended learning scheme as the research foundation. In the research process, the teaching effect of Baihui computer network curriculum is analyzed and concluded from three aspects:

(1) After adopting the blended learning scheme in The Computer Network, the vast majority of students obtain a significant improvement which can be seen from the student achievement analysis chart and their learning interest are obviously stimulated.

(2) The data in Table I and Table II illustrate that each statistical index as well as students' scores have been greatly improved after the cloud computing assisted instruction is applied in the blended learning scheme. Meanwhile, T test in Table III is carried out, indicating the importance of cloud computing assisted instruction in the teaching process of computer network and the advantages of the blended learning scheme.

(3) The assisted teaching platform for "Computer Network" is constructed under the guidance of the cloud computing assisted teaching theory. In the practical teaching process, Baihui platform is used as a teaching aid platform for the purpose of enhancing students' learning enthusiasm and their self-learning ability. That will be meaningful for research on the application of the cloud service in education.

In the further research, collaborative learning scheme and blended learning scheme are expected to be combined together and applied into the cloud computing assisted instruction to make greater progress.

\section{REFERENCES}

[1] Gadzhanov S, Nafalski A, Nedic Z. "Computerised Measurement Laboratory for Engineering Students". World Transaction on En- gineering and Technology Education. 2014,vol.12,no.3, pp.380385

[2] Abdulkareem A A. "Information Technology Intergration in Higher Education: A Novel Approach for Impact Assessment." International Journal of Emerging Technologies in Learning, 2014,vol.9, no.6, pp. 32-36. http://dx.doi.org/10.3991/ ijet.v9i6.4036

[3] Chuenyeh R, Chen Y C, Kuo S H, Chung P. "The Effect of Problem-based Learning on Enhancing Students' Workforce Competence." World Transaction on Engineering and Technology Education,2011,vol.9, no.4,pp. 380-385.

[4] Zhao N, Xia M J, Xu Z Q, Mi W J, Shen Y F. "A Cloud Computing-based College-enterprise Classroom Traning Method." World Transaction on Engineering and Technology Education,2015, vol.13, no.1, pp.116-120.

[5] Varona D, Capretz L F, Pinero Y. "Personality types of Cuban Software Developers." Global Journal of Engineering Education, 2011,vol.13,no.2,pp.77-81.

[6] Yang B. "On the Cloud Computing Assisted Instruction in the Design of Collaborative Learning Mechanism." Modern Education Technology. 2012,vol.19,no.11,pp.95-98.

[7] Ma Q, Fu Y R. "Research on Design of collaborative Learning Supported by Cloud Computing Aided Instruction-CCAI". Journal of Ningbo Polytechnic. 2011,vol.15,no.5,pp.59-61.

[8] Shang Y L, Gao F Z. "Research on the Application of Cloud Computer Assisted Instruction". Journal of Anyang Normal University. 2012,vol.22,no.5,pp.126-128.

[9] Jiang N, Yang S, Yang X H. "Cloud Computing Assisted Instruction Platform Based on Zoho Wiki". Journal of Shenyang Normal University. 2012,vol.30,no.2,pp.232-235.

[10] Xing Y J, Tan P, Zhang G W. "Applicaton Research Based on Cloud Computing Assisted Instructions and Blended Learning". Journal of Ningbo Institute of Education. 2015,vol.17,no.4,pp.1923.

[11] Xue H, Zhao Y P. "Preliminary Study of Low-Carbon Information CCAI Platform". Value Engineering. 2014,vol.23,no.3,pp.15-17.

[12] Fang N. "Using Tablet PCs to Quickly Assess Students' Problemsolving Performance in An Engineering Dynamics Classroom." World Transaction on Engineering and Technology Education.2012,vol.10, no.4,247-252.

[13] Zhang X D, Kang S Q, Hou M L, Liu X L. "Design and Implementation of A New-type Cloud Computing Examination System." Journal of Emerging Technologies in Learning,2015,vol.10, no.4,pp.28-33. http://dx.doi.org/10.3991/ijet.v10i4.4611

\section{AUTHORS}

Z.Y. Sun is working with School of Computer and Information, Luoyang Institute of Science and Technology, Luoyang, 471023, China. He is now in School of Electronics and Information Engineering, Xi'an Jiaotong University, Xi'an, 710048, China, (e-mail: lylgszy@163. com).

Y.X. Shu is working with School of Computer and Information, Luoyang Institute of Science and Technology, Luoyang, 471023, China. (e-mail: yxshu@ lit. edu.cn).

The authors are grateful for the supports provided by National Natural Science Foundation of China (No. 61503174) and Natural Science Foundation of Henan Province (No.14B520099). Submitted 31 January 2016. Published as resubmitted by the authors 20 February 2016. 